\title{
Quiste de prepucio deformante en un recién nacido
}

\section{Deforming foreskin cyst in a newborn}

\author{
Rubén Martín Alvarez-Solís ${ }^{1 *}$, Elías Córdova-Sastre ${ }^{1}$, Armando Quero-Hernández², \\ David Bulnes-Mendizábal ${ }^{3}$ y Florencio Álvarez-Herber ${ }^{1}$ \\ ${ }^{1}$ Servicio de Cirugía Pediátrica de NEOKIDS, Hospital Ángeles de Villahermosa, Tabasco; '2División de Pediatría del Hospital General Dr. Aurelio Valdivieso, \\ Oaxaca; ${ }^{3}$ Servicio de Anatomía Patológica del Hospital de Alta Especialidad del Niño "Dr. Radolfo Nieto Padrón", Villahermosa, Tabasco. México
}

\section{Resumen}

Los quistes del prepucio son lesiones muy raras. En general, son asintomáticos y no tienen repercusión en la función sexual. Muchos de ellos se presentan al nacimiento, pero usualmente suelen ser diagnosticados en la adolescencia y en el adulto. Reportamos el caso clínico de un paciente recién nacido, de 4 días de edad, con una masa de $3.5 \mathrm{~cm}$ de diámetro aproximadamente en la piel dorsal del prepucio, que se descubrió desde el momento de su nacimiento. El quiste fue resecado por completo y se realizó circuncisión para fines de estética. El examen histopatológico reveló un quiste mucoide por mucosa uretral ectópica en la piel del prepucio. No se observó recurrencia durante un año de seguimiento de su cirugía.

PALABRAS CLAVE: Quiste prepucial. Quiste uretral ectópico. Masa en pene. Quiste mucoide.

\begin{abstract}
Penile cysts are uncommon lesions. In general, they are asymptomatic and do not interfere with sexual function. Most of them are present since birth, but usually they are only detectable in adolescence or adulthood. We report a clinical rare case of a newborns of 4 days of birth with a $3.5 \mathrm{~cm}$ diameter nodule on the prepuce (dorsal face), which appeared of birth. The cyst was excised by circumcision and a histopathologic study was performed. Histopathologic examination revealed a mucoid cyst by ectopic urethral mucoid of penis skins. No recurrence was observed at a 6 months follow-up after of surgery.
\end{abstract}

KEY WORDS: Prepucial cyst. Urethral cyst ectopic. Penis mass. Mucoid cyst.

\section{Introducción}

Los tumores y las malformaciones congénitas del pene no son muy frecuentes ${ }^{1}$. Una investigación extensa en la literatura reporta menos de 200 casos publicados ${ }^{2}$. El prepucio es una cubierta mucocutánea especializada para aislar el glande y el meato uretral de los agentes físicos y contaminantes, manteniendo su humedad y su sensibilidad ${ }^{3}$. Los quistes del pene se pueden clasificar en: a) quistes del rafe medio, que son los más comunes y se localizan en la línea media o sobre la parte ventral del prepucio, caracterizados por tener una capa de células epiteliales mucinosas columnares y pseudoestratificadas; b) quistes mucoides, caracterizados por presentar mucosa uretral ectópica, que pueden localizarse sobre el glande o el prepucio y tienen una capa de células mucinosas con epitelio columnar estratificado; y c) quistes epidérmicos de inclusión, que son usualmente observados sobre el pene aunque también se encuentran frecuentemente

\author{
Correspondencia: \\ *Rubén Martín Álvarez-Solís \\ Paseo Usumacinta, 710, Torre $7^{\circ}$ \\ Col. Tabasco \\ C.P. 2000 , Villahermosa, Tab., México \\ E-mail: rubenalsolecito@ hotmail.com
}

Fecha de recepción: 05-03-2018

Fecha de aceptación: 10-10-2018

DOI: 10.24875/CIRU.18000221
Cir Cir. 2019;87:92-95

Contents available at PubMed www.cirugiaycirujanos.com 
en la piel escrotal, y se caracterizan por tejido o epitelio derivados de las células y las glándulas de la piel $\left.\right|^{2,3}$.

Se presentan el caso de un paciente recién nacido con deformación del pene secundaria a un quiste mucoide simple y una revisión de la literatura.

\section{Caso clínico}

Se trata de un varón de 20 días de edad que presenta desde su nacimiento una masa en el prepucio que deforma al pene (Fig. 1). La diuresis era normal a través de un orificio permeable en la masa del prepucio. Exploración física: peso $4 \mathrm{~kg}$, tórax y cardiopulmonar sin compromiso, abdomen normal, ambos testículos en escroto; destaca la deformidad del pene, caracterizada por una masa de aspecto quístico que parece depender exclusivamente de la piel del prepucio, no es obstructiva y se palpa de borde redondeados, no dolorosa y no fija a planos profundos ni al glande. La ultrasonografía reveló una masa de aspecto quístico, con un diámetro de $4 \times 3 \mathrm{~cm}$. Se realizaron resección del quiste y circuncisión con la técnica de League $^{4}$, de doble circular, sin complicación alguna, manejándose en forma ambulatoria. Los controles posoperatorios no mostraron recidiva a 1 año de la cirugía. El análisis histopatológico reportó como descripción macroscópica: masa nodular de $3.5 \mathrm{~cm}$ de diámetro recubierta por piel delgada del prepucio, la cual no muestra alteraciones, la masa es renitente y drena un fluido mucoide transparente y filante. Al corte se identifica una cavidad parcialmente tabicada, pero de interior liso, brillante y grisáceo, conteniendo moco filante transparente (Fig. 2). La descripción microscópica fue: los cortes muestran una piel delgada con haces musculares entrelazados en el corion. La cavidad con pared fibrosa y un recubrimiento epitelial columnar cilíndrico estratificado muco-productor de una sola capa de espesor; esta imagen corresponde a la de un quiste mucoide por mucosa uretral ectópica. No hay evidencia de malignidad (Fig. 3).

\section{Discusión}

La piel del pene constituye una envoltura delgada, fácilmente deslizable sobre los planos profundos y con una coloración ligeramente más oscura que el resto del tegumento. En la zona más distal se encuentra el prepucio, que forma un manguito cutáneo que envuelve al glande mediante el surco balanoprepucial, y otra distal o anterior libre conocida con el nombre de orificio prepucial ${ }^{5}$.

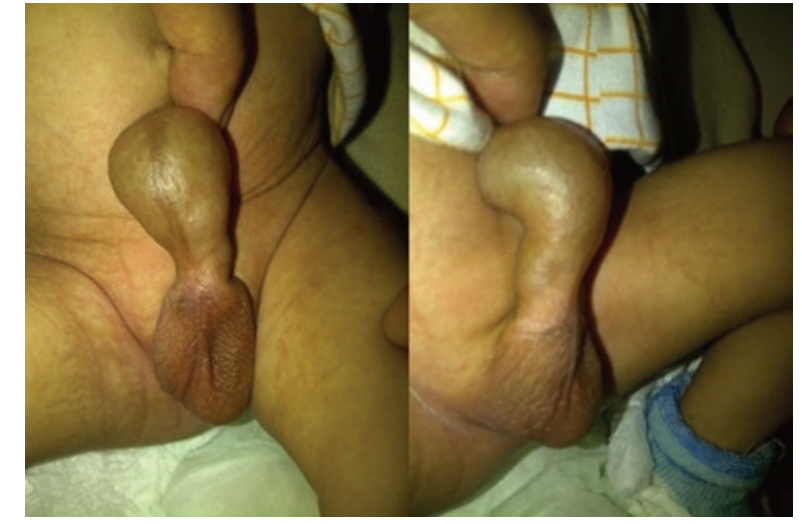

Figura 1. Deformidad del pene producida por el quiste.

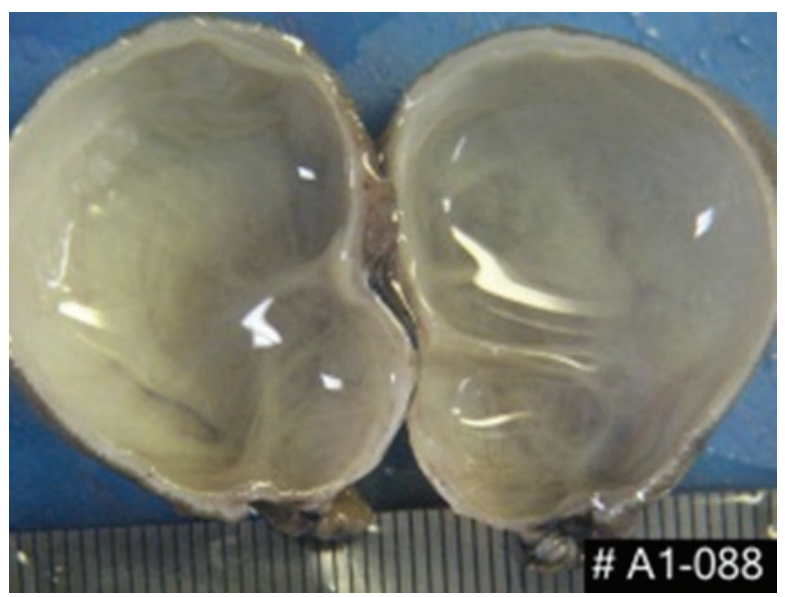

Figura 2. Quiste con epitelio columnar y líquido mucinoide.



Figura 3. Se aprecia una fina capa de células columnares, probablemente por uretra ectópica.

Se ha fundamentado que los quistes pueden desarrollarse a través de la línea media desde el ano hasta el meato uretral. Muchos de ellos se presentan desde el nacimiento, como nuestro caso, pero usualmente se diagnostican en la adolescencia o en la vida adulta, como se refiere en algunos reportes ${ }^{6-8}$.

Shiraki ${ }^{6}$ refiere que los quistes mucoides del pene son una afección benigna, que no se reportan con 
frecuencia y que no están asociados a traumatismo, infección ni circuncisión, y en su mayoría se presentan sobre la superficie ventral del glande del pene; en esto difiere nuestro caso, que se presentó sobre la superficie dorsal.

El diagnóstico diferencial según varias series, entre ellas la de Shiraki ${ }^{6}$ y la de Nagore, et al. ${ }^{7}$, incluye quistes epidérmicos, lipomas, esteatocitomas, quistes dermoides, quistes pilonidales, glándulas de Tyson y divertículos uretrales. Otros diagnósticos diferenciales son el quiste mucoso del pene, el quiste genitoperineal del rafe medio, el quiste parameatal, el hidrocistoma y el cistoadenoma apocrino del pene, los cuales pueden ser considerados como sinónimos ${ }^{8,9}$.

Es importante hacer énfasis en evitar confundirlos con quistes parauretrales, como mencionan Willis, et al..$^{10}$ en su artículo, ya que esto puede pasar con frecuencia, sobre todo cuando se desarrollan en la parte ventral.

Los quistes mucoides del pene principalmente se desarrollan sobre la superficie ventral, pero pueden encontrarse sobre la piel o la superficie dorsal del pene. Suelen ser asintomáticos y no obstruyen la uretra, pero pueden complicarse por infección o traumatismo. Los reportes en adolescentes y adultos están relacionados con dificultad en el acto sexual, y de ahí la importancia de la intervención en edad temprana, como en nuestro caso, que se resolvió de recién nacido ${ }^{11}$.

Los hallazgos de la pieza de patología demostraron que se trataba de un quiste mucoide, el cual incluye una línea de epitelio columnar pseudoestraficado que está frecuentemente asociado con mucosa intraepitelial o glándulas mucosas ectópicas de la uretra. Cuando esto sucede, la mucosa uretral ectópica es secuestrada en la piel del pene durante el desarrollo embrionario del feto ${ }^{11}$.

El tratamiento de elección es la resección del quiste. Otsuka, et al..$^{11}$ y Cardoso, et al. ${ }^{12}$ sugieren la circuncisión si está sobre la piel del prepucio en el glande, y en nuestro caso estaba más que indicado por la «deformidad» que preocupaba a los padres y así hacer la apariencia del pene más estética.

La patogénesis de esta enfermedad no está del todo bien entendida, y de ahí que surjan varias teorías de desarrollo de estos quistes de rafe medio. La uretra se forma como resultado de la fusión de las capas uretrales y el envolvimiento del surco uretral durante el desarrollo. La primera teoría establece que el tejido atrapado puede ocurrir en el tiempo o en un estadio mas tardío de formación de la uretra como un defecto de fusión de las capas uretrales o un sobrecrecimiento anómalo del epitelio, el cual es secuestrado y luego crece independientemente del cierre primario del rafe medio. Otras teorías proponen que los quistes de rafe medio también pueden ser causados por un secuestro anómalo en el desarrollo de las glándulas periuretrales de Littre. Estas teorías, explicadas por Yalta, et al. ${ }^{1}$, describen la presencia de células mucoides intraepiteliales y estructuras glandulares en algunos casos. Varios autores ${ }^{1-3}$ sugieren que pueden desarrollarse por el bloqueo de los conductos parauretrales. De acuerdo con la primera teoría, según la naturaleza del tejido secuestrado o atrapado será la línea del quiste que pueda presentarse. Para ello se han reconocido cuatro tipos diferentes: 1) epitelio columnar pseudoestraficado (si las células uretrales proximales son secuestradas); 2) epitelio celular escamoso (si las células uretrales distales son atrapadas); 3) epitelio glandular (si las glándulas periuretrales son secuestradas); y 4) de tipo mixto. Varios artículos ${ }^{1,2,5,7,8}$ afirman que el tipo mixto es el más común. Es muy raro encontrar células ciliadas en los quistes de rafe medio, de tal manera que solo encontramos cinco casos reportados en la literatura inglesa ${ }^{1,2}$.

Según la literatura revisada y nuestros hallazgos de patología, este caso podríamos catalogarlo como quiste mucoide de tipo mixto, por contener epitelio y glándulas uretrales. Este quiste también se ha reportado en la literatura y se conoce como quiste genitoperineal, quiste mucoide, quiste parameatal, hidrocistoma, cistoadenoma apocrino y quiste uretroi$d^{4,5}$. Si las células del lumen presentan secreción mucosa, como en nuestro caso, puede ser interpretado como cistoadenoma o hidrocistoma ${ }^{5,7}$.

En muchos pacientes el quiste es asintomático, 0 no reconocido en la niñez, siendo su presentación sintomática en la adolescencia o durante el inicio de las relaciones sexuales. Se ha reportado un caso que se presentó después de una intensa relación sexual. Las indicaciones de cirugía son la prevención del dolor durante el coito, pero más frecuentemente por «estética», razón y preocupación de los padres, que fue la indicación de la cirugía de nuestro paciente ${ }^{12}$.

Las opciones de tratamiento incluyen escisión local y aspiración con aguja fina si el paciente no quiere la cirugía; sin embargo, esta técnica está relacionada con recurrencia ${ }^{13}$. Una simple aspiración no se recomienda para el tratamiento. Subsecuentemente, la 




Figura 4. Circuncisión. Aspecto final del pene del paciente.

marsupialización o la exteriorización del quiste pueden realizarse en quistes grandes, pero los resultados no son satisfactorios cosméticamente. La escisión completa del quiste es lo ideal. En general no hay reportes de complicaciones en la literatura revisada, a excepción de unas pocas como la formación de una fístula uretrocutánea en un quiste mucoso ventral de rafe medio. En el presente caso, la indicación de escisión del quiste y circuncisión (Fig. 4) fue el tratamiento ideal desde el punto de vista «estético" y de la función sexual, y es el recomendado en la literatura ${ }^{13,14}$.

\section{Conclusión}

Los quistes de rafe medio del pene, al igual que en el prepucio, no son frecuentes. Por su gran tamaño, está indicada su extirpación quirúrgica y así obtener el diagnóstico histopatológico definitivo, dejando una apariencia lo más estética posible.

\section{Responsabilidades éticas}

Protección de personas y animales. Los autores declaran que para esta investigación no se han realizado experimentos en seres humanos ni en animales.

Confidencialidad de los datos. Los autores declaran que han seguido los protocolos de su centro de trabajo sobre la publicación de datos de pacientes.

Derecho a la privacidad y consentimiento informado. Los autores declaran que realizaron el consentimiento informado que consta en el expediente del paciente y guardan la privacidad del paciente no mostrando datos que pudieran identificarlo.

\section{Bibliografía}

1. Yalta T, Kazındır G, Oz Puyan F, Tastekin E, Usta U, Ciftci T, et al. Mucoid cyst of the penile skin: a rare entity. African Journal of Urology. 2010;16:132-3.

2. Amaranathan A, Sinhassan S, Dasiah S. Median raphe cysts of the prepucial skin, with triple histological linings: a case report and review of the literature. J Clin Diagn Res. 2013;7:1466-8.

3. Urahashi J, Hara H, Yamaguchi Z, Morishima T. Pigmented median raphe cysts of the penis. Acta Derm Venereol. 2000;80:297-8.

4. Montalvo A, Álvarez R. Manual de procedimientos en cirugía pediátrica. Interamericana-McGraw Hill; México. 1999.

5. Verma SB. Canal-like median raphe cysts: an unusual presentation of an unusual condition. Clin Exp Dermatol. 2009;34:e857-8.

6. Shiraki IW. Parametal cysts of the glans penis: a report of 9 cases. J Urol. 1975;114:544-8.

7. Nagore E, Sánchez-Motilla JM, Febrer MI, Aliaga A. Median raphe cysts of the penis: a report of five cases. Pediatr Dermatol. 1998;15:191-3.

8. Krauel L, Tarrado X, García-Aparicio L, Lerena J, Sunol M, Rodó J, et al. Median raphe cysts of the perineum in children. Urology. 2008;71: 830-1.

9. López-Candel E, Roig Álvaro J, López-Candel J, Fernández Dozagarat S, Soler J, Hernández Bermejo JP, et al. Quistes del rafe medio perineal en la infancia. An Esp Pediatr. 2000;52:395-7.

10. Willis HL, Snow BW, Cartwright PC, Wallis MC, Oottamasathien S, deVries C. Parameatal urethral cysts in prepubertal males. J Urol. 2011; 185:1042-5.

11. Otsuka T, Ueda $Y$, Terauchi M, Kinoshita Y. Median raphe (parameatal) cysts of the penis. J Urol. 1998;159:1918-20.

12. Cardoso R, Freitas JD, Reis JP, Tellechea O. Median raphe cyst of the penis. Dermatol Online J. 2005;11:37.

13. Koga K, Yoshida Y, Koga M, Takeshita M, Nakayama J. Median raphe cyst with ciliated cells of the penis. Acta Dermato-Venereol. 2007;87:542-3.

14. Taylor JR, Lockwood AP, Taylor AJ. The prepuce: specialized mucosa of the penis and its loss to circumcision. Br J Urol. 1996;77:291-5. 